\title{
Frequent Errors in Chinese EFL Learners' Topic-Based Writings
}

\author{
Huifang Zhan ${ }^{1}$ \\ ${ }^{1}$ School of Foreign Languages, Beihai College of Beijing University of Aeronautics and Astronautics, Beihai, \\ China \\ Correspondence: Huifang Zhan, School of Foreign Languages, Beihai College of BUAA, 536000 Beihai, China. \\ Tel: 86-138-7897-1002. E-mail: jennyzhan100@yahoo.com
}

Received: January 19, 2015 Accepted: February 25, 2015 Online Published: April 23, 2015

doi:10.5539/elt.v8n5p72 URL: http://dx.doi.org/10.5539/elt.v8n5p72

\begin{abstract}
This paper investigated a large number of errors found in the topic-based writings of Chinese EFL learners, especially provided an analysis on frequent errors, to find useful pedagogical implications for English grammar teaching and writing instruction in Chinese EFL setting. Students' topic-based writings were examined by the author. The findings suggest that misuse of tense and verb form was the most frequent error in Chinese students' writings. Others include those in spelling, use of particular words and phrases, Chinese-English expression, singular and plural form of nouns, parts of speech, non-finite verbs, run-on sentences, pronouns and so on. Teachers should pay due attention to all of the errors, especially those frequent ones, and try to find out what leads to those errors, thus, they may give their students effective grammar and writing instructions to help them with English learning.
\end{abstract}

Keywords: frequent error, topic-based writing, ungrammatical pattern, Chinese EFL learners, pedagogical implication

\section{Introduction}

Language teaching requires teachers to describe not only the target language (TL) but also the learners' version of the TL, which Corder (1971) called as learner's idiosyncratic dialect of the TL standard and Selinker (1972, 1992) called it their Interlanguage (IL). To describe learners' version of the TL, it is necessary to examine their utterances. Corder $(1975$, p. 207) pointed out that "the study of the whole performance data from individual learners" is performance analysis while "the study of erroneous utterances produced by groups of learners" is error analysis (EA). This paper is to provide an error analysis on Chinese learners' version of English in writing. Carl James (2001, p. 1) defined a language error as an unsuccessful bit of language. He pointed that learners' errors are a register of their current perspective of the TL (2001, p. 7). Corder (1967) made points that errors are significant in three aspects: they tell the teacher what needs to be taught; they tell the researcher how learning proceeds; and they are a means whereby learners test their hypotheses about the second language (L2). Johnson (2002, p. 59) argued that errors hold vital clues about the process of EFL learning, rather like the pain that may tell the doctor more than all the parts that do not hurt. All shows that teachers and learners will benefit from various forms of feedback on the errors, so it is necessary to focus on language learners' errors.

Errors are made by learners whether the language is spoken or written. English writing has become one of the important means to test English learning results. Accuracy is regarded as a significant criterion in assessment of English writing and plays an important role in the evaluation of English learning. However, in Chinese EFL learners' writings, errors are always a major factor to damage meaning and writing quality. Incorrect language use is reported as having negative impact on non-native speakers' perception of L2 writing quality (Johns, 1997; Johnson \& Roen, 1989; Hinkel, 2002), therefore, it is significant to have writing errors analyzed.

James (2001) points out that error analysis is the study of linguistic ignorance, the investigation of what people do not know and how they attempt to cope with their ignorance. Learners' ignorance of TL can be expressed in terms of four categories: grammaticality (well-formedness), acceptability, correctness, strangeness and infelicity. Grammaticality involves forms, context-free, while acceptability involves contexts. It is grammar who decides whether something said or written by a learner is grammatical, and it is the users who decide whether an utterance is acceptable. Cross-classification of them gives four possible combinations (James, 2001): [+Grammatical (GR) +Acceptable (ACC)], [+GR -ACC], [-GR +ACC], [-GR -ACC]. Correctness is related to 
the prescriptive normative standards. A piece of language, like "with Tom and I", may be acceptable by native speakers at first, but reflection about it may lead to judge it is rejected because "with Tom and me" is correct. Its rejection is based on a metalinguistic decision. Strangeness and infelicity result from "linguistically strange" word combinations (Allerton, 1990), including four types: those inherently strange (by using "glasnost" instead of words like "openess' or "transparency"), those semantically disharmonious (e.g. wet water), simple ungrammaticality and locutional deviance (e.g. He was listening at me when I put the statement.). Because the latter two can be considered as either $[+\mathrm{G},-\mathrm{ACC}]$ or $[-\mathrm{G},+\mathrm{ACC}]$, the paper mainly focus on the first two.

Apparently, errors made by EFL learners should be treated differently. Some errors may be taken with a more liberal attitude and others have to be taken seriously. Some errors have to be EFL teachers' priority and should be eradicated. The aim of the study is to observe, identify and categorize Chinese EFL learners' errors in their English writing so as to find and analyze the frequent errors, with the hope of generalizing useful pedagogical implication for grammar teaching and English writing in China.

\section{Method}

\subsection{Participants and Data}

Writing samples are collected from the essays written by the full-time undergraduate students of a third-rate university in Guangxi Autonomous Region, in the southwest of China. They are English majors and in their second year of college. They started English learning at about 9 years of age. Their English learning duration stretches from 11 to 14 years.

Those students were asked to produce three topic writings at different times during one semester when they were taking the course, basic English writing. The three topics are: "One of My Summer Holidays" (Writing 1), "A Description of a Person" (Writing 2) and "Whether Students Should Be Encouraged to Go into Business" (Writing 3), which are the three major types of writing - narration, description and argumentation. Each essay is required no less than 200 words. 177 writings samples are collected from the students in three classes (Table 1).

Table 1. The number of writing samples from different classes

\begin{tabular}{lllll}
\hline Class & Writing 1 & Writing 2 & Writing 3 & Total \\
\hline Class 1 & 10 & 15 & 14 & 39 \\
Class 2 & 30 & 19 & 22 & 71 \\
Class 3 & 23 & 20 & 24 & 67 \\
Total & 63 & 54 & 60 & 177 \\
\hline
\end{tabular}

\subsection{Analysis Procedures}

According to the three levels of a language, the error types are decided from three aspects: substance, text and discourse. The former two are the major concern of this paper. When learners are operating the substance systems, substance errors such as spelling errors and punctuation errors may occur. When learners are operating the lexico-grammatical system to produce or process text, text errors may arise, including lexical errors and grammatical errors. Since grammar has traditionally been discussed in terms of morphology and syntax, grammar errors contain morphological and syntactical errors, those in word structure and in structures larger than word such as phrase, clause, sentence and paragraphs. All subjects' writings are reviewed elaborately from the two levels. Error patterns are identified and the actual frequent error patterns are summarized. Identical errors on the same words or sentences in one writing sample are ignored, but those under the same error pattern but related to different words or sentences are calculated. Error frequency was calculated in order to identify the most frequent errors.

\section{Results and Discussion}

All together 38 error types are classified. 1423 tokens of errors are collected and filed in total from all the writing samples. Our findings show that the top six error types are in tense and verb form, spelling, use of particular words and phrases, Chinese-English expression, singular/plural form of nouns, parts of speech. Other frequent errors include those in non-finite verbs, run-on sentences, pronouns, clauses and so on. The error types, number of tokens and total percentage are shown in Table 2. 
Table 2. Error types and the number of tokens

\begin{tabular}{|c|c|c|c|c|c|c|}
\hline No. & Errors in & Writing 1 & Writing 2 & Writing 3 & Token Number & Error Percentage \\
\hline 1 & tense and verb form & 72 & 134 & 171 & 377 & 26.49332 \\
\hline 2 & spelling & 37 & 31 & 48 & 116 & 8.151792 \\
\hline 3 & use of particular words and phrases & 43 & 53 & 20 & 116 & 8.151792 \\
\hline 4 & Chinese-English expression & 24 & 22 & 43 & 89 & 6.254392 \\
\hline 5 & singular/plural form of nouns & 20 & 38 & 26 & 84 & 5.903022 \\
\hline 6 & parts of speech & 13 & 23 & 45 & 81 & 5.6922 \\
\hline 7 & non-finite verbs & 27 & 22 & 17 & 66 & 4.638089 \\
\hline 8 & run-on sentences & 24 & 21 & 21 & 66 & 4.638089 \\
\hline 9 & pronouns & 5 & 16 & 20 & 41 & 2.881237 \\
\hline 10 & clauses & 4 & 23 & 12 & 39 & 2.740689 \\
\hline 11 & be+ adj & 8 & 16 & 11 & 35 & 2.459592 \\
\hline 12 & diction & 9 & 17 & 6 & 32 & 2.24877 \\
\hline 13 & articles & 8 & 8 & 15 & 31 & 2.178496 \\
\hline 14 & modal verbs & 9 & 5 & 12 & 26 & 1.827126 \\
\hline 15 & collocation & 5 & 17 & 3 & 25 & 1.756852 \\
\hline 16 & distinguishing words and phrases & 4 & 15 & 5 & 24 & 1.686578 \\
\hline 17 & prep. & 4 & 10 & 10 & 24 & 1.686578 \\
\hline 18 & capitalization & 6 & 8 & 6 & 20 & 1.405481 \\
\hline 19 & voice & 6 & 4 & 9 & 19 & 1.335207 \\
\hline 20 & $\mathrm{be}+\mathrm{v}$ & 6 & 11 & 1 & 18 & 1.264933 \\
\hline 21 & adverbs'position & 2 & 6 & 9 & 17 & 1.194659 \\
\hline 22 & fragmentary sentences & 0 & 12 & 2 & 14 & 0.983837 \\
\hline 23 & comparative and superlative degree & 2 & 8 & 3 & 13 & 0.913563 \\
\hline 24 & parallel structure & 0 & 9 & 1 & 10 & 0.702741 \\
\hline 25 & -ed, -ing as adj. & 6 & 3 & 0 & 9 & 0.632467 \\
\hline 26 & possessions & 3 & 4 & 1 & 8 & 0.562193 \\
\hline 27 & prep. +ving & 1 & 1 & 4 & 6 & 0.421644 \\
\hline 28 & inverted sentence & 2 & 1 & 2 & 5 & 0.35137 \\
\hline 29 & emphatic sentence & 0 & 2 & 0 & 2 & 0.140548 \\
\hline 30 & exclamation sentence & 0 & 2 & 0 & 2 & 0.140548 \\
\hline 31 & repetition & 0 & 1 & 0 & 1 & 0.070274 \\
\hline 32 & punctuation & 0 & 1 & 0 & 1 & 0.070274 \\
\hline 33 & conj. & 0 & 1 & 0 & 1 & 0.070274 \\
\hline 34 & dangling modifiers & 1 & 0 & 0 & 1 & 0.070274 \\
\hline 35 & There be... & 0 & 1 & 0 & 1 & 0.070274 \\
\hline 36 & logical order of paragraphs & 0 & 1 & 0 & 1 & 0.070274 \\
\hline 37 & structure & 0 & 1 & 0 & 1 & 0.070274 \\
\hline 38 & number of words & 0 & 1 & 0 & 1 & 0.070274 \\
\hline Total & & & & & 1423 & 100 \\
\hline
\end{tabular}


According to our calculation, the average number of error tokens in each essay is 8.0.

\subsection{Errors in Tense and Verb Form}

The error in tense and verb form ranks the first among all the error tokens, which totals at 337 and accounts for approximately $26 \%$ of all error types. Among the errors, those in tense take up about $13 \%$ while those in verb form take up another $13 \%$. Tense errors refer to using a wrong tense that does not correspond to the language context (Examples a-b). Errors in verb form means that writers may know what tense should be used in the context, but write down the wrong verb form, as a result of not knowing the correct form or forgetting to change the verb to the needed form or changing into a wrong form (Examples c-j). Some of the examples from our data are as follows.

a) He learned English by himself for 2 years in Beijing. (has learned)

b) I just taught them about one month. (have just taught them for)

c) It enable the students to be independent and build up their self-confidence. (enables)

d) What does my father looks like? (look)

e) She not allowed me to fool around my time. (didn't allow)

f) She has became the most important one in my life. (has become)

g) Once you have choose the major, you should be responsible for it. (chosen)

h) Going into business is just one of the ways they choosed. (chose)

i) In a poor family, she grown up into a brave woman. (has grown)

j) I losed it. (lost)

*Note. Those underlined are erroneous bits of language and those in the brackets are one of the revised versions according to the writers' intention in their writings.

Verb form errors in the students' writings can be mainly further subcategorized: a) lack or overgeneralization of subject-verb(S-V) agreement of the 3rd person singular; b) confusion about past tense (pt.) and past participle (pp.); c) omission of an auxiliary; d) creation of a nonexistent verb form. According to English grammar, a verb agrees with its subject both in person and in number. The verb takes a corresponding form in terms of the subject, but verb singularity in simple present is often forgotten by Chinese students (Example c). It is the same true of the pt./pp. errors, which sometimes are not caused by tense, but by forgetting the forms of pt. and pp. or by confusing them (Examples f-j). In interrogative sentences, the tense marker is often placed on the auxiliary verb or the modal verb. In Example d, the auxiliary verb is "does". The learner gets this part right, but he in fact marks the tense twice - as well as having "does", he puts an -s on the end of the verb "look".

The errors in the S-V agreement of the 3rd person singular are prominent with totals at 94 in the data and account for about one half of the wrong verb forms and $7 \%$ of all errors. Mistaking $\mathrm{pt} / \mathrm{pp}$ as $\mathrm{pp} / \mathrm{pt}$ and others take up about $6 \%$ in all errors (Table 3 ).

Table 3. Errors in tense and verb form

\begin{tabular}{llllll}
\hline Errors in & Writing 1 & Writing 2 & Writing 3 & Token Number & Error Percentage \\
\hline Tense & 63 & 97 & 31 & 191 & 13.42235 \\
$3^{\text {rd }}$-person singular & 3 & 29 & 62 & 94 & 6.605762 \\
pt./pp. and others & 6 & 8 & 78 & 92 & 6.465214 \\
\hline
\end{tabular}

Chinese EFL learners often find difficulties in choosing tenses for contexts. They are confused by verb forms for different tenses. One of the reasons is that Chinese Mandarin has no such conjugation. They often make errors in choice of tenses and verb forms even they know what tense is actually used in the context.

\subsection{Errors in Spelling}

Spelling error is the second most frequent error type in all writing samples. Memorizing words is one of difficult tasks for Chinese EFL learners. It is more concerned during their high school years. When students are in high school, teachers have rigid tasks about memorizing words and rigorous check with them. Once they enter college, most of them have much less pressure from learning. Our survey is conducted in a third-rate university in China, 
whose students mostly do not have a good English foundation and they have relatively poor learning persistence. Therefore, misspelling in writing is a serious problem. In the writing samples, some top spelling errors are as following: alway (always), nowdays/nowaday (nowadays), ture (true) and turely (truely), unforgetable (unforgettable), weather (whether), talktive (talkative). Other errors are embrassing (embarrassing), benificial (beneficial), besises/beside (besides), choise (choice), cignificant (significant), ecist (exist), experince (experience), funning (funny), heself (himself), grammer (grammar), guidence (guidance), latter (later), legand (legend), luckly (luckily), meself (myself), ourself (ourselves), theirselves (themselves), planing (planning), retogether (reunion), nobel (noble), sellman (salesman), strengthes (strengthness), taught (tought), strick (strict). In some phrases, there are still spelling errors like "from than on" (then), "hit issues" (hot), "lost of" (lots of), "quite school" (quit). Such errors include omission of a letter or more letters, reversal of letters, misselection from two letters that can present the same sound or from two homophones, confusion in word parts like stems or affixes because of learners' accent or mispronunciation. It suggests that improving students' spelling is a lasting task for both teachers and students themselves.

\subsection{Errors in the Use of Particular Words and Phrases}

The misuse of some particular words and phrases ties for the second most common error in the writing samples. Some typical words or phrases have special usages, quite different from other ones. Turton (1995, p. vii) called them as word grammar errors, distinct from other "system Grammar errors", and pointed out that they arise when learners violate "rules that control the use of particular words". Chinese students make errors frequently in such words as "make", "like" and "thank" (Table 4), and "let". There are also errors in using phrases like "be afraid of doing" or "be afraid that ..." and "too ...to..."

Table 4. Error frequency of "make", "like" and "thank"

\begin{tabular}{llllll}
\hline Errors in & Writing 1 & Writing 2 & Writing 3 & Token Number & Error Percentage \\
\hline make & 3 & 4 & 1 & 8 & 0.562193 \\
like & 2 & 5 & 1 & 8 & 0.562193 \\
thank & 0 & 2 & 0 & 2 & 0.140548 \\
\hline
\end{tabular}

There are such ungrammatical patterns in the data as the following:

a) A story made me changed my opinion. (made me change)

b) The beautiful scenery made me don't want to go back. (not want)

c) The park just like my second home. (is just like)

d) I still thank to her real help. (thank her for her)

e) Thank God let me met her and let us became good friends. (for letting me meet her; letting us become)

f) We shouldn't afraid of help others waste our time or believe others want to cheat us. (be afraid that helping others wastes )

g) She was too tired to get ill. (She was so tired that she got ill.)

Errors in using the words like "happen", "just"/"only" and "as"/"with" also occur frequently in Chinese learners' writings, but they do not in the data. Examples are following.

h) It happened some unpleasant things. (Some unpleasant things happened.)

i) I can't express how I feel about my mother in just words. (in only these/just in these)

j) As the development of the society, there are more and more aged people. (With)

In fact, there is another form of misuse of words. In English there are lexical categories like verbs, adjectives, articles, prepositions and so on. There are rules that control such word types. If an adjective is used as predicative, a copula verb precedes it. However in Chinese, the copula is often absent in such a setting, so students always leave out the copula in English. In Chinese there are no articles, so article omission and misuse of definite/ indefinite articles in English are very common. If all the tokens above are included in a broad type, such an error type may be Top 2 (Table 5). 
Table 5. Errors in some lexical categories

\begin{tabular}{llllll}
\hline Errors in & Writing 1 & Writing 2 & Writing 3 & Token Number & Error Percentage \\
\hline be+ adj. & 8 & 16 & 11 & 35 & 2.459592 \\
articles & 8 & 8 & 15 & 31 & 2.178496 \\
modal verbs & 9 & 5 & 12 & 26 & 1.827126 \\
prep. & 4 & 10 & 10 & 24 & 1.686578 \\
be + v & 6 & 11 & 1 & 18 & 1.264933 \\
position of adverbs & 2 & 6 & 9 & 17 & 1.194659 \\
v-ed, v-ing as adj. & 6 & 3 & 0 & 9 & 0.632467 \\
Prep. + v-ing & 1 & 1 & 4 & 6 & 0.421644 \\
conj. & 0 & 1 & 0 & 1 & 0.070274 \\
Total & 37 & 56 & 58 & 151 & 10.61138 \\
\hline
\end{tabular}

Examples are as follows:

a) They still willing to help people. (are still willing )

b) We went to dining hall. (the dining hall)

c) When you doing business, it's a unknown investment. (do, an)

d) She must did it. (must do)

e) We went back to our hometown by our own. (on)

f) They both are worked in the same factory. (worked)

g) They also can learn something from failure. (can also)

h) I felt more exciting. (excited)

i) After graduated from the primary school, I know ... (After graduating)

j) Tom has played guitar when he was 7 years old. (has been playing; since)

*Note. Those bits of language with double lines beneath (including those in the whole paper) are also erroneous, but not affiliated to the error type being discussed.

\subsection{Chinese-English Expression}

Chinese-English expression is the fourth most frequent error in students' writing samples. By the term Chinese-English expression, we mean students resort to Chinese sentence structure, word order, and direct literal translation from Chinese to English in their writing (Sun, 2014). Effects of one learning habit on another are known as transfer in psychology. There are two sorts of transfer: positive and negative. In EFL learning, there are both positive and negative transfer of Chinese. One factor that influences the occurrence of transfer is learner level. It has been suggested that lower level learners are particularly prone to negative transfer because they have fewer resources at their disposal in the target language. They rely heavily on their native language to help them in times of trouble (Johnson, 2002:63). Our findings are in agreement with the conclusion above. For those lower levels of English learners, this kind of errors is identified as more common. They are so greatly affected by their mother tongue that they often ignore the basic grammatical structure of English. Whether in simple and short or complex and long sentences, they may resort to L1 equivalents or Chinese expression in the word sequence. And in some more complicated sentences students make more errors. Typical examples are listed as follows:

a) Don't be polite. (Just make yourself at home)

b) It's very waste of time. (a waste)

c) I have a great many friends. But one of them I like much better than any other. (I like one of them much more than any others.)

d) Some people think that should not be allowed or encouraged students to go into business. (students should not be allowed and encouraged)

In Example a, the sentence is well-formed. It is understandable and correct in Chinese sequence, but it is not 
accepted in the context that someone is invited to your home for dinner and you said "Don't be polite" in English. For those evaluators who don not know anything about Chinese, the sentence may be absurd. Such a word-for-word equivalent is [+GR, $-\mathrm{ACC}]$ in English. In Example d, it is confusing that no subject precedes the predicate "should not be allowed or encouraged" and the word "students" follows it. It may be regarded as an error of missing the subject and the writer's confusion about passive and active voices. It is true, but what mainly leads the writer to his error is word sequence of Chinese. Because when the subject "students" is omitted, the word order in Chinese makes the sentence still understandable and correct if the learner gets the voice right ("should not allow or encourage students"), but it is not the case in English.

It is clear that some learners have not grasped the rules well. They turn to their native language. Lado (1957:2) put forward "contrastive analysis (CA) hypothesis" to find out what made some things easy for learners and other things difficult: those elements that are similar to the learners' native language will be simple for him, and those elements that are different will be difficult. Although the claim of Lado has been disputed, it reminds Chinese EFL teachers of being aware of the differences between Chinese and English. Wei and Fei (2003) define Chinese English (Chinglish) as an interlanguage. They think it is usually manifested as Chinese-style syntax with English words, Chinese phonological elements in pronunciation or grammatical variations that attempt to follow Standard English rules but miss the rule. Chinese evaluators are sometimes also affected by their mother tongue and they are very careful about detecting such deviant bits of English in the writings of their Chinese students and take efforts to make them understand.

\subsection{Errors in Singular/Plural Form of Nouns}

The fifth frequent error is in singular and plural forms of nouns. 84 out of 1423 error tokens are identified as a lack of singular or plural markers and disagreement, which totally account for about $6 \%$. Chinese has no inflections. Plural $-s$ in English appears redundant, so "help stranger" (Example a) occurs. It's not strange that learners forget the marker "a/an" for singular (Example b) and sometimes irregular plural forms (Example c). There are also both singular and plural markers, one showing the singular and the other showing the plural, resulting in disagreement (Example e-g). In English, there are countable and uncountable nouns, regular and irregular plural forms, which make learners confused.

a) We should help stranger. (strangers)

b) It's really hard job. (a really hard job)

c) When child make mistakes, father ... (children)

d) We can learn knowledges and gain experience. (knowledge)

e) If you are a good candidates, you'll have more chances to be employ. (a good candidate; employed)

f) This summer holidays, ... (holiday)

g) These money help a lot of people have a good life. (The money)

h) We have many free time. (much)

\subsection{Errors in Parts of Speech}

Chinese students are often confused by the different forms of one word, its noun, verb, adj., adv. etc. Some words with a suffix -ly are not adv. but adj.. If words like "lack" and "respect" are used as verbs, "lack sth." and "respect sb." are used, instead of "lack of sth.", "respect for sb.", in which "lack" and "respect" are nouns. Those totally make Chinese learners frustrated. They mix up the different forms of a word, its noun, verb, adj., adv., if there are any. Examples are following.

a) I become more and more confidence. (confident)

b) It will be effected not only the students' successful but also their view of life. (affect, success )

c) No one can success so easy. (succeed, easily)

d) They lack of work experience. (lack)

e) It's their own choose whether they help or not. (choice)

\subsection{Other Error Types}

Other frequent error types include those on non-finite verbs, run-on sentences, pronouns, diction, clauses, and so forth. As for non-finite verbs, students may misuse present participle, gerund, infinitive (Examples a-c). Run-on sentences (Examples d-e) can be revised in different patterns, by using another simple sentence or using a clause. It depends on the writer's intention and the context. As to the errors in personal or possessive pronouns 
(Examples f-g), students may either use the objective case instead of the needed subjective, or just the reverse. They may miss a possessive or use an unspecified reference, making the meaning vague.

a) Help someone is not difficult to us. (Helping)

b) We should help strangers and it would bring lots of benefits, such as make us more unite, make our life more easier, make the world more peaceful. (making, united; making, easier, making)

c) The best way to integrate into society that the whole society should encourage the college students go into business. (is that, to go into)

d) I was attracted by her smile, her smile made me feel comfortable and relaxed. (. Her smile/, which)

e) After school, she went to teachers' home, learned for two or three hours and then went back home, she must finish her homework. (. She)

f) She never asked me for anything but her gave me a lot. (she)

g) Everyone has own dream. (his own)

In our data, there are errors made because of false selection. Errors in diction involve wrong choice of words and expressions (Examples a-b). Students also confuse two or more words with similar spellings, pronunciations or meanings like "pass", "passed" and "past", "respect" and "expect", "later" and "latter", "also" and "either", "if" and "whether", "very" and "very much", "hard", "hard-working" and "hardly" (Examples c-g). Distinguishing those words is similar to diction because it involves diction as well, but it is a little different from diction. When learners make errors in distinguishing words, there is always another one word or other two or more words that may interfere with them and lead them to make a false selection. In this aspect, students have to make clear about them. The following are the examples drawn from our data.

a) I am the smallest granddaughter. (youngest)

b) My father often called the teacher to ask my exhibition in school. (performance)

c) I past my interview and I became a formal employee. (passed)

d) As what I respecting, summer holiday is coming. (expect)

e) It was the later. (latter)

f) If students should be allowed or encouraged to go into business has become a hot topic among people. (whether)

g) Mr. Wen also didn't want to leave us. (didn't want to leave us either)

In clauses, deviance arises when there is a miss of a relative pronoun (Examples a-b), a miss of a needed subject (Examples c-d), incorrect sequence of the subject and the verb. In Example e, it applies the interrogative formation rule in the clause, but omits to invert the subject and the predicate.

a) I gained the most from trip is that knowing how important the parent-child relationship is. (What I gained)

b) There are some people hold opposite opinions. (some people who hold)

c) Students should choose a job suitable for their career and hope that students can enjoy their lives. (I hope)

d) This was my first time saw fireflies. (that I saw)

e) I didn't know what did it mean. (what it meant)

\section{Conclusion}

This study mainly discusses Chinese EFL learners' most frequent errors in their topic-based writings. The top six are the errors in tense and verb form, spelling, use of particular words and phrases, Chinese-English expression, singular/plural form of nouns, parts of speech. Other frequent errors include those in non-finite verbs, run-on sentences, pronouns, clauses and so on. All of the errors should be paid due attention to by Chinese EFL learners and teachers. And those frequent ones should be their priorities.

The ultimate cause of the errors is learners' linguistic ignorance of the TL. Due to lack of declarative knowledge, learners use strategies to compensate for their ignorance. Instead of silence, learners try to express themselves by alternative means. In the substitutive language, inappropriate L1 transfer arises. Apart from the negative L1 transfer, the second reason for the errors is misapplying avoidance. When learners resort to L1, they find L1 can not help, either they are ignorant of the L1 equivalent, or L1 lacks an equivalent. They turn to the communication strategy of paraphrase and circumlocution, and their self-assessment about the alternative 
version may not be right. Such errors are still caused by ignorance of the TL. Different learners who use different strategies to cope with some feature of the TL that they are equally ignorant of may make different errors, so a third reason for the errors are the strategies that learners use. Some other reasons may be external ones, such as teachers' imprecise explanations and misleading materials.

Whatever reasons cause the errors, a fact cannot be denied that errors made by learners are related to their cognitive process. After our survey, students were told our findings and the teachers also conducted explicit instruction on those ungrammatical errors in class once because it is believed that it may raise learners' awareness of their errors. After the teaching practice, we find that classroom analysis and instruction are really helpful, but not so helpful. During one or two months after instruction on the errors, students' writings had improved, but at the end of the semester, a large number of those errors appeared again in their final exam writings. It can be concluded that Chinese EFL teaching has attached great importance to language points, but obviously students do not learn well. They have difficulty in English writing. Error correction is a cognitive process and errors cannot be removed until they have a clear awareness of them. Therefore, it is necessary for teachers to regard the instruction as a long-term project by asking students to correct peers' writings, handing in their revised writings or doing some exercises like correcting sentence errors. It is also helpful to find new approaches to help our students master language knowledge and apply it to their written and oral productions accurately and fluently. One caveat the author needs to mention here is that due to the limited data for each writing type and the deficiency in classification of the error types, it is necessary to conduct long-term projects to improve English writing and English grammar teaching in China.

\section{References}

Allerton, D. (1990). Linguistically strange word combinations. In M. Bridges (Ed.), On strangeness (pp. 109-120). Tubingen: Gunther Narr.

Corder, S. P. (1967). The significance of learner's errors. International Review of Applied Linguistics, 5(4), 161-170. Reprinted in Corder, S. P. (1981). Error analysis and Interlanguage (pp. 1-13). Oxford: Oxford University Press. http://dx.doi.org/10.1515/iral.1967.5.1-4.161

Corder, S. P. (1971). Idiosyncratic dialects and error analysis. International Review of Applied Linguistics, 9(2), 147-160. Reprinted in Corder, S. P. (1981). Error analysis and Interlanguage (pp. 14-25). Oxford: Oxford University Press. http://dx.doi.org/10.1515/iral.1971.9.2.147

Corder, S. P. (1975). Error analysis, Interlanguage and second language acquisition (Survey Article). Language Teaching and Linguistics Abstracts, 8, 201-218. http://dx.doi.org/10.1017\%2fS0261444800002822

Hinkel, E. (2002). Teaching grammar in writing classes: Tenses and cohesion. In E. Hinkel, \& S. Fotos (Eds.), New perspective on grammar teaching in second language classrooms (pp. 181-196). New York, NY: Routledge.

James, C. (2001). Errors in language learning and use: Exploring error analysis. Beijing: Foreign Language Teaching and Research Press.

Johns, A. (1997). Text, role, and context: Developing academic literacies. Cambridge, UK: Cambridge University Press.

Johnson, D., \& Roen, D. (1989). Richness in writing. New York, NY: Longman.

Johnson, K. (2002). An introduction to foreign language learning and teaching. Beijing: Foreign Language Teaching and Research Press.

Lado, R. (1957). Linguistics across cultures. Ann Arbor: University of Michigan Press.

Selinker, L. (1972). Interlanguage. International Review of Applied Linguistics, 10(3), 209-231. http://dx.doi.org/10.1515\%2firal.1972.10.1-4.209

Selinker, L. (1992). Rediscovering Interlanguage. London: Longman.

Sun, X. (2014). Ungrammatical patterns in Chinese EFL learners' free writing. English Language Teaching, 7(3), 176-183. http://dx.doi.org/10.5539/elt.v7n3p176

Turton, N. D. (1995). ABC of common grammatical errors: For learners and teachers of English. London: Macmillan Education Limited.

Wei, Y., \& Fei, J. (2003). Using English in China. English Today, 19(4), 42-47. http://dx.doi.org/10.1017\%2fS0266078403004073 


\section{Copyrights}

Copyright for this article is retained by the author(s), with first publication rights granted to the journal.

This is an open-access article distributed under the terms and conditions of the Creative Commons Attribution license (http://creativecommons.org/licenses/by/3.0/). 